
\title{
25 Research Soure \\ Barriers to and Facilitators of Return to Work in Head and Neck Cancer Patients with in the First Six Months Post-Treatment
}

\section{Bing-Shen Huang}

Linkou Chang Gung Memorial Hospital: Chang Gung Memorial Hospital

Chien-Yu Lin

Linkou Chang Gung Memorial Hospital: Chang Gung Memorial Hospital

\section{Ya-Lan Chang}

Linkou Chang Gung Memorial Hospital: Chang Gung Memorial Hospital

\section{Ching-Fang Chung}

Linkou Chang Gung Memorial Hospital: Chang Gung Memorial Hospital

Shu-Ching Chen ( $\nabla$ shuching@gw.cgust.edu.tw)

Chang Gung University of Science and Technology https://orcid.org/0000-0002-7921-1964

\section{Research Article}

Keywords: Cancer, Psycho-Oncology, Head and neck cancer, return to work, barriers, facilitators, Karnofsky Performance Status, subjective health, survey methodology, multivariate analysis

Posted Date: January 3rd, 2022

DOI: https://doi.org/10.21203/rs.3.rs-1150490/v1

License: (c) (1) This work is licensed under a Creative Commons Attribution 4.0 International License. Read Full License 


\section{Abstract \\ Objective}

To identify the factors associated with barriers to and facilitators of return to work (RTW) in head and neck cancer (HNC) patients in the first six months post-treatment.

\section{Methods}

This cross-sectional study examined HNC patients who completed treatment from the outpatient radiation department of a single cancer center in northern Taiwan from October 2018 to July 2020. Demographic and clinical characteristics were recorded, and patients were assessed using the Return to Work Barrier Scale, Return to Work Facilitator Scale, Distress Thermometer, Numeric Rating Scale, and Karnofsky Performance Status Scale questionnaires.

\section{Results}

Of the $106 \mathrm{HNC}$ patients surveyed, $54.7 \%$ successfully RTW. Barriers to RTW included patient-perceived worst health status, greater symptom burden, and age $\geq 55$ years. These factors explained $34.6 \%$ of the variance in overall barriers to RTW. Facilitators of RTW were lower psychological distress and who did not receive reconstruction surgery. These factors explained $17.9 \%$ of the variance in facilitators to RTW.

\section{Conclusion}

Patient-perceived health status and age most strongly influence RTW in HNC patients. HNC patients who can RTW should be encouraged to do so, and clinician awareness of potential barriers can aid patients in their RTW.

\section{Introduction}

Head and neck cancer (HNC) is among the most common types of cancer. HNC refers to cancers which develop in the head and neck region, including the nasal cavity, oral cavity, pharynx, larynx, and salivary gland [1, 2]. HNC accounts for $3 \%$ of all cancers in the United States, with approximately 53,000 US citizens developing HNC annually and 10,800 dying from the disease [1]. In Taiwan, approximately 6,000 $\mathrm{HNC}$ cases are diagnosed annually [3], many of whom are of working-age [4] and a main source of family income.

Disease progression and the adverse effects of treatment impact the ability of HNC patients to transition back to work after completing treatment, especially in those who perform manual labor $[5,6]$. Return to work (RTW) refers to the ability or preparation of an individual to return to a job after a cancer diagnosis 
or during or after treatment [6-8]. RTW can optimize recovery [9], help patients maintain their personal identity $[10,11]$, promote psychosocial well-being [12], and enhance the development of a healthy lifestyle [12].

The sequelae of treatment often affect the ability of HNC patients to work. The rate of RTW varies; 65.6$83 \%$ of patients RTW within 6 months $[13,14]$ and $48 \%$ RTW within one year after treatment [15]. Patients who RTW earlier benefit from the greater perceived health associated with work, more connections in their social relationships, and a decline in the financial impact of the disease $[16,17]$.

Barriers to RTW following HNC include the adverse effects of treatment such as fatigue, speech and eating problems, pain, changes in appearance $[13,16]$, and psychological and health-related distress $[13$, 16]. Factors shown to facilitate and support a RTW of cancer patients include co-workers' assistance [17], flexible schedules [18], support from employers [17], a friendly work environment, and positive employment policies [17].

Although previous studies have explored these issues, most research has focused on patients who survived head and neck cancer (HNC) [5, 20,21], data from Western countries [14, 22] or India [13], qualitative research [23], and the perspective of peers and employer [24]. Therefore, the purposes of this study were to: (1) examine the status of RTW in working-age HNC patients within six months of ending treatment; (2) compare the levels of symptom burden, psychological distress, patient-perceived health status, barriers to RTW, and facilitators of RTW of those who did and did not RTW; and (3) identify the factors associated with barriers to and facilitators of RTW in HNC patients within the first six months post-treatment.

\section{Methods}

\section{Design and sample}

A cross-sectional, descriptive, and correlational design was used in this study. Consecutive sampling was conducted to recruit subjects from the otolaryngology, plastic/reconstructive surgery, and radiation oncology outpatient departments of a medical center in northern Taiwan between October 2018 and July 2021. The inclusion criteria were: (1) new diagnosis of HNC; (2) part-time or full-time employment at the time of cancer diagnosis; (3) completion of treatment within the past 6 months; and (4) aged 20-64.5 years (retirement age in the Taiwan is 65 years). Patients were not eligible to participate if they had a mental disorder, an unstable systemic disease (active infection or other underlying disease), recurrent HNC, or physical performance $<60$ on the Karnofsky Performance Status Scale (KPS) [25].

\section{Ethical considerations}

The study was approved by the medical center Institutional Review Board (Number: 201801245B0) and was found to conform to the principles of the Declaration of Helsinki. Following a detailed explanation of 
the study and its procedures, subjects who agreed to participate were asked to provide signed informed consent before data collection.

\section{Data Collection}

After completing treatment, HNC patients regularly make follow-up visits with the otolaryngology, plastic/reconstructive surgery, or radiation oncology outpatient departments. Participants who met the inclusion criteria filled in the structured questionnaires by self-report in the consulting rooms. The interview lasted approximately 10 to 15 minutes.

\section{Measures}

\section{Return to Work Barrier Scale}

The Return to Work Barrier Scale (RTWBS) was used to assess the barriers to RTW [26]. The 17-item scale includes two subscales: the impact of cancer and its treatment ( 9 items) and cognitive and emotional representations of illness (8 items). Each item is scored from 0 to 7, with higher scores indicating a greater barrier to RTW. Previous studies using the RTWBS have indicated that this instrument has good test-retest reliability, concurrent validity, predictive validity, and discriminant validity [26]. The RTWBS was translated into Chinese, and five HNC and cancer care experts confirmed its content validity. The Cronbach's alpha for the RTWBS was 0.85 .

\section{Return to Work Facilitator Scale}

The Return to Work Facilitator Scale (RTWFS) was developed based on HNC patients' RTW experiences derived from literature review $[12,27,28]$. and a previous study [5]. Each item is scored on a scale of 1 to 5 , with a higher score indicating greater facilitation of RTW. The content validity index was evaluated by five experts with working experience in HNC-related cancer care and was determined to be 0.98 . The Cronbach's alpha for the RTWFC data was 0.88 .

\section{Distress Thermometer}

The Distress Thermometer (DT), used to assess the level of psychological distress [29]. The DT is a visual analog scale that participants use to rate their level of distress over the preceding 7 days; scores range from 0 (none) to 10 (extreme). A previous study has determined that a cut-off score of 4 or greater indicates distress [30]. A previous study confirmed the validity of the Chinese version of the DT [31].

\section{Numeric Rating Scale}

The Numeric Rating Scale (NRS) was used to assess patients' symptom burden and health status. The NRS is a unidimensional measure of various symptoms or problems [32,33]. The NRS is a horizontal bar or line with whole numbers (0-10 integers) used to reflect the intensity of the patient's symptom or problem, with 0 indicating "no such symptom or problem at all" and 10 indicating "extreme severity of the symptom or problem" [32]. For each symptom or problem, the patient's subjective perception is rated as low (NRS score $\leq 3$ ), moderate (NRS score 4-6), or high (NRS score $\geq 7$ ) [32]. In this study, subjects were 
asked to rate their level of symptom burden and their perception of their health status. The NRS has been tested and shown to have satisfactory psychometric properties [32].

\section{Karnofsky Performance Status Scale}

Patients' performance status was measured using the KPS, which ranges from $100 \%$ (normal function) to $0 \%$ (death) [25]. KPS has been widely used, and previous studies have reported it to be reliable for studies of cancer patients in Taiwan [5]. An inter-observer reliability coefficient of 0.99 was reported in the present study.

\section{Demographic and Clinical Characteristics}

The demographic data included age, sex, employment status at diagnosis, marital status, education level, and type of occupation (unskilled/semi-skilled worker; skilled worker; clerk/shop owner/farm owner; semiprofessional; professional). Clinical characteristics included cancer subsite, cancer stage, medical treatment, and time since the completion of treatment.

\section{Statistical analysis}

SPSS version 26.0 (IBM Corp., Armonk, NY, USA) was used for data analysis. Descriptive statistics were used to summarize patient demographic and clinical characteristics. Chi-square test, Fisher's exact test, and independent t-test were used to test the homogeneity between patients who did and did not RTW, as well as the differences in symptom burden, psychological distress, patient-perceived health status, barriers to RTW, and facilitators of RTW. The 10 top-ranked barriers to RTW of patients who did and did not RTW were selected as "the top 10 significant barriers to RTW" and were measured using the RTWBS [26]. Multiple regression analysis was conducted to identify the factors associated with barriers to RTW and facilitators of RTW. The independent variables included age ( $\leq 54$ years vs. $\geq 55$ years), time since the completion of treatment, education level, reconstruction surgery (no vs. yes), symptom burden, psychological distress, and patient-perceived health status.

\section{Results}

\section{Patients characteristics}

Of 108 eligible patients initially recruited, two declined to participate because they had no time or interest, for a response rate of $98.2 \%$. We classified patients into the not RTW group, which included those who quit their job after diagnosis or took a leave of absence, sick leave, or an early retirement; and the RTW group, which included those who returned to the same work or changed into another line of work. Of the 106 patients studied, 48 (45.3\%) did not RTW and 58 (54.7\%) did. The two groups did not differ significantly in age, marital status, cancer stage, type of treatment, or performance status (KPS). Those who did not RTW were more likely to be female $(p=0.002)$, have a less than senior high school education $(p=0.036)$, have cancer of the oral cavity $(p=0.027)$, and have a shorter time since the completion of treatment $(<5$ months $)(p=0.002)$ (Table 1$)$. 
Table 1

Patient characteristics $(N=106)$

\begin{tabular}{|c|c|c|c|c|}
\hline \multirow[t]{2}{*}{ Variable } & \multirow{2}{*}{$\begin{array}{l}\text { Not RTW } \\
(n=48)\end{array}$} & \multirow{2}{*}{$\begin{array}{l}\text { RTW ( } n=58) \\
\text { N(\%) / Mean } \\
\text { (SD) }\end{array}$} & \multirow[t]{2}{*}{$X^{2} / t$} & \multirow[t]{2}{*}{$p$} \\
\hline & & & & \\
\hline Age (years) & $52.23(7.47)$ & $52.10(7.83)$ & 0.084 & 0.933 \\
\hline \multicolumn{5}{|l|}{ Sex } \\
\hline Male & $46(95.8)$ & $57(98.3)$ & 0.570 & 0.020 \\
\hline Female & $2(4.2)$ & $1(1.7)$ & & \\
\hline Marital status & & & 1.094 & 0.295 \\
\hline Unmarried & 16(33.3) & $14(24.1)$ & & \\
\hline Married & $32(66.7)$ & $44(75.9)$ & & \\
\hline Education level & & & 8.520 & $0.036^{a}$ \\
\hline Elementary & $4(8.3)$ & $10(17.2)$ & & \\
\hline Junior high & $24(50.0)$ & $15(25.9)$ & & \\
\hline Senior high & 18(37.5) & $25(43.1)$ & & \\
\hline College and above & $2(4.2)$ & $8(13.8)$ & & \\
\hline Types of occupation & & & 8.620 & 0.013 \\
\hline Unskilled/ semi-skilled worker & $36(75.0)$ & $20(51.7)$ & & \\
\hline Skilled worker & $12(25.0)$ & $22(37.9)$ & & \\
\hline Clerk, shop, owner, farm owner & $0(0)$ & $6(10.3)$ & & \\
\hline Semi-professional & $0(0)$ & $0(0)$ & & \\
\hline Professional & $0(0)$ & $0(0)$ & & \\
\hline Status of return to work & & & - & - \\
\hline
\end{tabular}

$S D$, Standard Deviation.

$R T$, radiotherapy.

$C C R T$, concurrent chemoradiation therapy.

KPS, Karnofsky Performance Status.

a Fisher's exact test. 


\begin{tabular}{|c|c|c|c|c|}
\hline \multirow[t]{2}{*}{ Variable } & \multirow{2}{*}{$\begin{array}{l}\begin{array}{l}\text { Not RTW } \\
(n=48)\end{array} \\
\text { N(\%) / } \\
\text { Mean(SD) }\end{array}$} & \multirow{2}{*}{$\begin{array}{l}\text { RTW (n=58) } \\
\begin{array}{l}\text { N(\%) / Mean } \\
\text { (SD) }\end{array}\end{array}$} & \multirow[t]{2}{*}{$X^{2} / t$} & \multirow[t]{2}{*}{$p$} \\
\hline & & & & \\
\hline Not return to work & $48(100)$ & - & & \\
\hline - Quit job after diagnosis & $40(83.3)$ & - & & \\
\hline - Leave of absence & $2(4.2)$ & - & & \\
\hline - Sick Leave & $4(8.30)$ & - & & \\
\hline - Early retirement (pension) & $2(4.2)$ & - & & \\
\hline Return to work & - & $58(100)$ & - & - \\
\hline - Return to same work & - & $53(91.4)$ & & \\
\hline - Changed work & - & $5(8.6)$ & & \\
\hline Tumor site & & & 17.346 & $0.027^{a}$ \\
\hline Oral cavity & $44(91.3)$ & $46(79.3)$ & & \\
\hline Hypopharynx & $4(8.3)$ & $9(15.5)$ & & \\
\hline Larynx & $0(0)$ & $3(5.2)$ & & \\
\hline Cancer stage & & & 3.693 & 0.158 \\
\hline II & $5(10.4)$ & $10(17.2)$ & & \\
\hline III & $5(10.4)$ & $12(20.7)$ & & \\
\hline IV & $38(79.2)$ & $36(62.1)$ & & \\
\hline Medical treatment & & & 2.180 & $0.336^{a}$ \\
\hline Surgery + RT & $23(47.9)$ & 18(31.0) & & \\
\hline Surgery + CCRT & $21(43.8)$ & $26(44.8)$ & & \\
\hline CCRT & $4(8.3)$ & $14(24.1)$ & & \\
\hline
\end{tabular}

$S D$, Standard Deviation.

$R T$, radiotherapy.

$C C R T$, concurrent chemoradiation therapy.

KPS, Karnofsky Performance Status.

${ }^{a}$ Fisher's exact test. 


\begin{tabular}{|c|c|c|c|c|}
\hline \multirow[t]{2}{*}{ Variable } & $\begin{array}{l}\text { Not RTW } \\
(n=48)\end{array}$ & RTW (n=58) & \multirow[t]{2}{*}{$x^{2} / t$} & \multirow[t]{2}{*}{$p$} \\
\hline & $\begin{array}{l}\mathrm{N}(\%) / \\
\text { Mean(SD) }\end{array}$ & $\begin{array}{l}\mathrm{N}(\%) \text { / Mean } \\
\text { (SD) }\end{array}$ & & \\
\hline KPS score (level) & $99.38(2.45)$ & $100(0.00)$ & -1.948 & 0.054 \\
\hline 90 & $3(6.3)$ & $56(58.3)$ & & \\
\hline 100 & $45(93.8)$ & $100(100)$ & & \\
\hline $\begin{array}{l}\text { Time since the completion of treatment } \\
\text { (months) }\end{array}$ & $4.72(1.48)$ & $5.42(1.56)$ & -2.362 & 0.020 \\
\hline \multicolumn{5}{|l|}{$S D$, Standard Deviation. } \\
\hline \multicolumn{5}{|l|}{$R T$, radiotherapy. } \\
\hline \multicolumn{5}{|l|}{$C C R T$, concurrent chemoradiation therapy. } \\
\hline \multicolumn{5}{|l|}{ KPS, Karnofsky Performance Status. } \\
\hline a Fisher's exact test. & & & & \\
\hline
\end{tabular}

\section{Differences in symptom burden, psychological distress, patient-perceived health status, barriers to RTW, and facilitators of RTW in patients who did and did not RTW}

Patients did not RTW had higher levels of symptom burden $(t=3.945, p<0.05)$, psychological distress $(t=$ $6.364, p<0.05)$, barriers to RTW $(t=2.650, p<0.05)$, cancer and treatment impact barriers $(t=2.595$, $p<0.05)$, cognitive and emotional representations illness barriers $(t=2.118, p<0.05)$, lower facilitators of RTW $(t=-13.145, p<0.05)$, employer support $(t=-4.960, p<0.05)$, coworker support $(t=-9.647, p<0.05)$, positive communication ( $t=-8.025, p<0.05)$, positive workplace $(t=-1.220, p>0.05)$, and positive employment policy $(t=-1.372, p>0.05)$ than those who did RTW (Table 2). 
Table 2

Differences in symptom burden, psychological distress, patient-perceived health status, barriers to RTW, and facilitators of RTW in patients who did and did not RTW $(N=106)$

\begin{tabular}{|c|c|c|c|c|c|c|}
\hline \multirow[t]{2}{*}{ Variable } & \multicolumn{2}{|c|}{$\begin{array}{l}\text { Not return to work } \\
(n=48)\end{array}$} & \multicolumn{2}{|c|}{$\begin{array}{l}\text { Return to work } \\
(n=58)\end{array}$} & \multirow[t]{2}{*}{$t$} & \multirow[t]{2}{*}{$p$} \\
\hline & Mean & SD & Mean & SD & & \\
\hline Symptom burden (NRS) & 32.08 & 11.66 & 24.83 & 7.07 & 3.945 & 0.001 \\
\hline Psychological distress (DT) & 7.40 & 1.54 & 5.45 & 1.59 & 6.364 & 0.001 \\
\hline $\begin{array}{l}\text { Patient-perceived health status } \\
\text { (NRS) }\end{array}$ & 34.38 & 4.69 & 31.84 & 4.18 & -0.567 & 0.572 \\
\hline Barriers to RTW (RTWBS) & 71.56 & 7.43 & 67.17 & 9.28 & 2.650 & 0.009 \\
\hline - Cancer and treatment impact & 39.10 & 4.91 & 36.43 & 5.57 & 2.595 & 0.011 \\
\hline $\begin{array}{l}\text { - Cognitive and emotional } \\
\text { representations illness }\end{array}$ & 32.46 & 3.81 & 30.74 & 4.42 & 2.118 & 0.037 \\
\hline Facilitators of RTW (RTWFC) & 9.63 & 1.75 & 13.72 & 1.40 & -13.145 & 0.001 \\
\hline - Employer support & 2.15 & 0.71 & 2.78 & 0.59 & -4.960 & 0.001 \\
\hline - Coworker support & 2.25 & 0.53 & 3.19 & 0.48 & -9.647 & 0.001 \\
\hline - Positive communication & 1.94 & 0.73 & 2.91 & 0.47 & -8.025 & 0.001 \\
\hline - Positive workplace & 1.79 & 0.46 & 1.93 & 0.67 & -1.220 & 0.225 \\
\hline - Positive employment policy & 1.40 & 0.49 & 1.53 & 0.70 & $\overline{1.3720}$ & 0.173 \\
\hline
\end{tabular}

$S D$, standard deviation.

NRS, Numeric Rating Scale.

$D T$, Distress Thermometer.

RTWBS, Return to Work Barrier Scale.

RTWFC, Return to Work Facilitator Scale.

* $p<0.05, * * p<0.001$

\section{Differences in the top-ranked and mean barriers of RTW and not RTW patients}

In patients who did not RTW, the top five barriers to RTW were "fatigue or feeling exhausted" (mean=4.88, standard deviation $[S D]=1.88$ ), "level of performance" (mean=4.83, SD=0.69), "degree to which employee will experience cancer symptoms at work" (mean=4.75, SD=0.67), "physical symptoms" (mean=4.69, $S D=0.88$ ), and "emotional distress" (mean=4.65, $S D=1.08$ ). In patients who did RTW, the top five barriers 
to RTW were "physical symptoms" (mean=4.60, $S D=1.06$ ), "fatigue or feeling exhausted" (mean=4.59, $S D=1.12$ ), "level of performance" (mean=4.53, $S D=1.02)$, "degree to which employee will experience cancer symptoms at work" (mean=4.50, SD=0.94), and "degree of concern over cancer returning" (mean=4.24, SD=1.19) (Table 3).

Table 3

Differences in the top-ranked and mean barriers of RTW and not RTW patients $(N=106)$

\begin{tabular}{|c|c|c|c|c|c|c|c|}
\hline \multirow[t]{2}{*}{ Variable } & \multirow[t]{2}{*}{$\begin{array}{l}\text { Domain of Barriers } \\
\text { to RTW }\end{array}$} & \multicolumn{2}{|c|}{$\begin{array}{l}\text { Not return to } \\
\text { work }(n=48)\end{array}$} & \multicolumn{2}{|c|}{$\begin{array}{l}\text { Return to } \\
\text { work }(n=58)\end{array}$} & \multirow[t]{2}{*}{$t$} & \multirow[t]{2}{*}{$p$} \\
\hline & & Mean & SD & Mean & SD & & \\
\hline $\begin{array}{l}\text { 1. Fatigue or feeling } \\
\text { exhausted }\end{array}$ & $\begin{array}{l}\text { Cancer and } \\
\text { treatment impact }\end{array}$ & 4.88 & 1.88 & 4.59 & 1.12 & 0.980 & 0.329 \\
\hline 7. Level of performance & $\begin{array}{l}\text { Cancer and } \\
\text { treatment impact }\end{array}$ & 4.83 & 0.69 & 4.53 & 1.02 & 1.734 & 0.086 \\
\hline $\begin{array}{l}\text { 14. Degree to which } \\
\text { employee will experience } \\
\text { cancer symptoms at work }\end{array}$ & $\begin{array}{l}\text { Cognitive and } \\
\text { emotional } \\
\text { representations } \\
\text { illness }\end{array}$ & 4.75 & 0.67 & 4.50 & 0.94 & 1.545 & 0.125 \\
\hline 3. Physical symptoms & $\begin{array}{l}\text { Cancer and } \\
\text { treatment impact }\end{array}$ & 4.69 & 0.88 & 4.60 & 1.06 & 0.439 & 0.662 \\
\hline 2. Emotional distress & $\begin{array}{l}\text { Cancer and } \\
\text { treatment impact }\end{array}$ & 4.65 & 1.08 & 3.90 & 1.07 & 3.569 & 0.001 \\
\hline $\begin{array}{l}\text { 6. The unpredictability of } \\
\text { cancer }\end{array}$ & $\begin{array}{l}\text { Cancer and } \\
\text { treatment impact }\end{array}$ & 4.54 & 0.92 & 4.14 & 1.15 & 2.010 & 0.047 \\
\hline 4. Low confidence & $\begin{array}{l}\text { Cancer and } \\
\text { treatment impact }\end{array}$ & 4.54 & 1.09 & 3.91 & 1.10 & 2.941 & 0.004 \\
\hline $\begin{array}{l}\text { 13. Degree to which } \\
\text { cancer treatment impairs } \\
\text { employee's ability to work }\end{array}$ & $\begin{array}{l}\text { Cognitive and } \\
\text { emotional } \\
\text { representations } \\
\text { illness }\end{array}$ & 4.50 & 0.88 & 4.17 & 0.99 & 1.804 & 0.074 \\
\hline $\begin{array}{l}\text { 15. Degree of concern } \\
\text { over cancer returning }\end{array}$ & $\begin{array}{l}\text { Cognitive and } \\
\text { emotional } \\
\text { representations } \\
\text { illness }\end{array}$ & 4.48 & 1.03 & 4.24 & 1.19 & 1.102 & 0.273 \\
\hline $\begin{array}{l}11 . \text { Degree to which work } \\
\text { is affected by cancer }\end{array}$ & $\begin{array}{l}\text { Cognitive and } \\
\text { emotional } \\
\text { representations } \\
\text { illness }\end{array}$ & 4.23 & 0.97 & 3.98 & 0.98 & 1.291 & 0.199 \\
\hline
\end{tabular}

Factors associated with barriers to RTW and facilitators of RTW 
Multiple regression analysis identified the factors significantly and independently associated with barriers to RTW, two dimensions of barriers to RTW, and facilitators of RTW (Table 4). Patients who perceived that they had the worst health status $(\beta=-0.346)$, who had greater symptom burden $(\beta=0.241)$, and who were $\geq 55$ years $(\beta=-0.207)$ were more likely to have greater overall barriers to RTW. These three factors explained $34.6 \%$ of the total variance in overall barriers to RTW. In terms of the cancer and treatment impact on RTW, barriers to RTW were patient-perceived worst health status $(\beta=-0.386)$, and those who received reconstruction surgery $(\beta=0.213)$. These two factors explained $21.9 \%$ of the total variance in cancer and treatment impact on barriers to RTW. Greater cognitive and emotional barriers to RTW were correlated with patient-perceived worst health status $(\beta=-0.484)$, greater symptom burden $(\beta=0.273)$, and being aged $\geq 55$ years $(\beta=-0.216)$. These three factors explained $35.2 \%$ of the total variance in cognitive and emotional barriers to RTW. Patients who had lower psychological distress $(\beta=-0.360)$ and who did not receive reconstruction surgery $(\beta=-0.200)$ were more likely to have more facilitators to RTW. These two factors explained $17.9 \%$ of the total variance in facilitators to RTW (Table 4). 
Table 4

Factors associated with barriers to RTW and facilitators of RTW $(N=106)$

\begin{tabular}{|c|c|c|c|c|c|c|c|}
\hline \multirow{2}{*}{$\begin{array}{l}\text { Domains of } \\
\text { barriers to TRW }\end{array}$} & \multirow{2}{*}{$\begin{array}{l}\text { Predictive } \\
\text { variable }\end{array}$} & \multirow{2}{*}{$\begin{array}{l}\text { Adjusted } \\
\mathrm{R}^{2}\end{array}$} & \multirow[t]{2}{*}{ Beta } & \multirow[t]{2}{*}{$F$} & \multirow[t]{2}{*}{$\mathbf{p}$} & \multicolumn{2}{|l|}{$95 \% \mathrm{Cl}$} \\
\hline & & & & & & Lower & Upper \\
\hline \multirow[t]{4}{*}{$\begin{array}{l}\text { Overall barriers to } \\
\text { RTW (RTWBS) }\end{array}$} & $\begin{array}{l}\text { Patient- } \\
\text { perceived health } \\
\text { status }\end{array}$ & 0.346 & -0.499 & 19.493 & 0.001 & -0.179 & -0.093 \\
\hline & $\begin{array}{l}\text { symptom } \\
\text { burden }\end{array}$ & & 0.241 & & 0.003 & 0.057 & 0.271 \\
\hline & $\begin{array}{l}\text { Age ( } \leq 54 \text { years } \\
\text { vs. } \geq 55 \text { years) }\end{array}$ & & -0.207 & & 0.010 & -0.416 & -1.058 \\
\hline & Constant & & & & 0.001 & 71.256 & 91.572 \\
\hline \multirow[t]{3}{*}{$\begin{array}{l}\text { Cancer and } \\
\text { treatment impact } \\
\text { on RTW (RTWBS) }\end{array}$} & $\begin{array}{l}\text { Patient- } \\
\text { perceived health } \\
\text { status }\end{array}$ & 0.219 & -0.386 & 15.718 & 0.001 & -0.095 & -0.036 \\
\hline & $\begin{array}{l}\text { Reconstruction } \\
\text { (no vs. yes) }\end{array}$ & & 0.213 & & 0.018 & 0.465 & 4.943 \\
\hline & Constant & & & & 0.001 & 35.536 & 40.367 \\
\hline \multirow[t]{4}{*}{$\begin{array}{l}\text { Cognitive and } \\
\text { emotional barriers } \\
\text { to RTW (RTWBS) }\end{array}$} & $\begin{array}{l}\text { Patient- } \\
\text { perceived health } \\
\text { status }\end{array}$ & 0.352 & -0.484 & 20.048 & 0.001 & -0.084 & -0.043 \\
\hline & $\begin{array}{l}\text { symptom } \\
\text { burden }\end{array}$ & प & 0.273 & & 0.001 & 0.039 & 0.141 \\
\hline & $\begin{array}{l}\text { Age ( } \leq 54 \text { years } \\
\text { vs. } \geq 55 \text { years) }\end{array}$ & & -0.216 & & 0.007 & -0.205 & -0.033 \\
\hline & Constant & & & & 0.001 & 32.408 & 42.183 \\
\hline \multirow[t]{3}{*}{$\begin{array}{l}\text { Facilitators of } \\
\text { RTW (RTWFC) }\end{array}$} & $\begin{array}{l}\text { Psychological } \\
\text { distress }\end{array}$ & 0.179 & -0.360 & 12.462 & 0.001 & -0.753 & -0.255 \\
\hline & $\begin{array}{l}\text { Reconstruction } \\
\text { (no vs. yes) }\end{array}$ & & -0.200 & & 0.028 & -2.285 & -0.135 \\
\hline & Constant & & & & 0.001 & 14.275 & 17.690 \\
\hline \multicolumn{8}{|c|}{ RTWBS, Return to Work Barrier Scale. } \\
\hline \multicolumn{8}{|c|}{ RTWFC, Return to Work Facilitator Scale. } \\
\hline \multicolumn{8}{|c|}{$\begin{array}{l}\text { Input independent variable: covariates included age ( } \leq 54 \text { years vs. } \geq 55 \text { years), time since the } \\
\text { completion of treatment (continuous score), educational level (continuous score), reconstruction (no } \\
\text { vs. yes), symptom burden (continuous score), psychological distress (continuous score), and patient- } \\
\text { perceived health status (continuous score). }\end{array}$} \\
\hline
\end{tabular}




\section{Discussion}

In the present study, $54.7 \%$ of HNC patients did RTW within the first six months post-treatment, a much lower rate of RTW than that that reported by Agarwal et al. [13] The differences in RTW status may have been influenced by age and education level. In our study, those who did RTW had a mean age of 52.10 years and most patients had a junior high (25.9\%) or senior high (43.1\%) school education; only $13.8 \%$ had an educational level of college or above. In the study of Agarwal et al., [13] the HNC patients who did RTW had an average age of 47 years and $25.6 \%$ had a graduate or postgraduate school education. In Taiwan, most HNC patients are blue-collar workers who work in skilled or unskilled jobs requiring a relatively high level of physical fitness [5]. Nutrition counseling and physical training extending into the post-treatment period are needed for such workers to RTW.

The results of this study showed that RTW patients reported higher levels of employer support, coworker support, and positive communication than patients those who did not RTW. These results are consistent with those of earlier studies by Johnsson et al. [34] and Nilsson [35], which indicated that social support from employers and coworkers is crucially important for cancer patients to RTW. Although more than half of patients did RTW within six months post-treatment, the difficulties in interpersonal interaction and communication which HNC patients can experience can result in an inability or disinclination to RTW. Healthcare providers should be aware of HNC patients' coping strategies for communication and maintaining interpersonal relationships within the workplace, and seek to provide care that enables them to RTW.

The present study examined HNC patients within six months of ending treatment. Both those who did and did not RTW rated highly the barriers to RTW as "fatigue or feeling exhausted," "level of performance," "degree to which employee will experience cancer symptoms at work," and "physical symptoms." These results are consistent with those of previous studies [13], which reported fatigue as the most common problem for HNC patients who did and did not RTW, and also that it was the most important factor in their decision to discontinue work. Therefore, enhanced patient education, exercise, energy conservation, and proper nutrition and hydration during and after treatment can help relieve patient fatigue and promote physical fitness.

Results of the present study showed that patient-perceived health status and being aged $\geq 55$ years were the most common factors associated with the overall barriers to RTW and cognitive and emotional barriers to RTW. These results are consistent with those of a previous study [36] which reported that younger age and good self-rated health are the primary facilitators of RTW. In addition, HNC patients typically will also have financial distress after diagnosis, which may cause greater symptom burden, decreased adherence to treatment recommendations, poorer health-related quality of life, and increased mortality risk [37, 38]. Health care providers should assess each patient's socioeconomic status and provide access to appropriate social resources in order to minimize financial distress and help patients have the resources they need to continue treatment. 
Similar to the results of previous studies [16, 39, 40], we found that patients who did RTW had lower emotional distress, less symptom burden, and more confidence than those who did not RTW. HNC treatment-related adverse effects generate physical and psychological distress and negatively impact one's ability to work. Healthcare providers can help their patients by discussing the work-related and disease-related problems they are likely to encounter when they RTW, and designing an individualization rehabilitation program to reduce psychological distress and improve the patient's confidence in social interactions.

\section{Limitations}

This study had several limitations. First, the present study examined HNC patients in the first six months post-treatment, but RTW is a dynamic process that changes over time. Longitudinal or long-term followup studies are also needed to identify changes in employment status and the factors related to RTW. Second, the sample consisted only of patients from a single medical center in northern Taiwan, and may not fully account for the effect of the differences in geographical and sociological factors between countries. Future studies may expand subject recruitment to different locations in order to compare the variation in effect on RTW.

\section{Conclusion}

We found that $54.7 \%$ of HNC patients RTW within the first six months post-treatment. Patients who perceived that they had a worse health status, had greater symptom burden, and were aged $\geq 55$ years had a greater overall barrier to RTW. Patient-perceived health status and age were the strongest factors affecting RTW.

\section{Clinical implications}

In the clinical care of HNC patients, addressing the barriers to and facilitators of RTW such as physical workload and work ability and incorporating the shared-care model can help patients in their decision to RTW.

\section{Declarations}

Funding: Chang Gung Memorial Hospital (grant number CMRPF1H0131) Research Program in Taiwan supported to Shu-Ching Chen.

Conflicts of interest/Competing interests: None declared.

Availability of data and material: The data that support the findings of this study are available from the corresponding author. Restrictions apply to the availability of these data, which were used under license for this study. Data are available from the authors with the permission of the Chang Gung Memorial Hospital Research Program (CMRP). 
Authors' contributions: All authors have agreed on the final version and meet at least one of the following criteria [recommended by the ICMJE (http://www.icmje.org/recommendations/)]:

- substantial contributions to conception and design, acquisition of data or analysis and interpretation of data;

- drafting the article or revising it critically for important intellectual content.

Study design: BSHuang\& SC Chen; Data collection and analysis: BS Huang, CY Lin, YL Chang, CF Chang, \& SC Chen; Manuscript preparation: BSHuang\& SC Chen

Ethics approval: All procedures performed in studies involving human participants were in accordance with the ethical standards of the University of Wisconsin Health Sciences IRB (Number: 201801245B0) and with the 1964 Helsinki Declaration and its later amendments or comparable ethical standards.

Consent to participate: Informed consent was obtained from all individual participants included in the study.

Consent for publication: This manuscript is original, is not plagiarized, and has not been published elsewhere.

This manuscript is not under consideration for publication in another journal, and will not be submitted elsewhere until the JSCC editorial process is completed.

All authors consent to the publication of the manuscript in JSCC, should the article be accepted by the Editor-in-chief upon completion.

\section{References}

1. Ferlay J, Soerjomataram I, Dikshit Ret al (2015)Cancerincidence and mortality worldwide: sources, methods and major patterns in GLOBOCAN 2012, Int J Cancer136: E359https://doi.org/10.1002/ijc.29210

2. Weiss J, Hayes DN (2013)Classifying squamous cell carcinoma of the head and neck: prognosis, prediction and implications for therapy.Expert Rev Anticancer Ther14:2292https://doi.org/10.1586/14737140.2014.863154

3. Taiwan cancer registry. 2015 annual report. Available from: http://crs.cph.ntu.edu.tw/. Accessed December 8, 2021.

4. Hsu WL, Yu KJ, Chiang CJ, Chen TC, Wang CP (2017) Head and neck cancer incidence trends in Taiwan, 1980 2014. Int J Head Neck Sci 1:180-189.https://doi.org/6696/IJHNS.2017.0103.05

5. Chen SC, Huang BS, Hung TM, Lin CY, Chang YL (2019) Impact of physical and psychosocial dysfunction on return to work in survivors of oral cavity cancer. Psychooncology28:1910- 
19https://doi.org/10.1002/pon.5173

6. Duijts SF, van Egmond MP, Spelten E et al (2014)Physical and psychosocial problems in cancer survivors beyond return to work: a systematic review. Psychooncology23:481492.https://doi.org/1002/pon.3467

7. Mehnert A (2011) Employment and work-related issues in cancer survivors. Criti Rev OncolHematol77:109-130.https://doi.org/1016/j.critrevonc.2010.01.004

8. Steiner JF, Nowels CT, Main DS (2010) Returning to work after cancer: Quantitative studies and prototypical narratives. Psychooncology19:115-124.https://doi.org/1002/pon.1591

9. Hoving JL, Broekhuizen MLA, Frings-Dresen MHW (2009) Return to work of breast cancer survivors: a systematic review of intervention studies. BMC Cancer9:117-127.https://doi.org/1186/1471-2407-9117

10. Peteet JR (2000) Cancer and the meaning of work. General Hospital Psychiatry 22: 200-2

11. Rasmussen DM, Elverdam B (2008) The meaning of work and working life after cancer: an interview study. Psychooncology17:1232-1238.https://doi.org/1002/pon.1354

12. Islam T, Dahlui M, Majid HA et al (2014)Factors associated with return to work of breast cancer survivors: a systematic review. BMC Public Health14:S8.https://doi.org/1186/1471-2458-14-S3-S8

13. Agarwal J, Krishnatry R, Chaturvedi P et al (2017)Survey of return to work of head and neck cancer survivors: A report from a tertiary cancer center in India. Head Neck39:8938https://doi.org/10.1002/hed.24703

14. Verdonck-de Leeuw IM, van Bleek WJ, Leemans CR, de Bree R (2010)Employment and return to work in head and neckcancersurvivors.Oral Oncol46:56https://doi.org/10.1016/j.oraloncology.2009.11.001

15. Handschel J, Gellrich NC, Bremerich A, Krüskemper G (2013)Return to work and quality of life after therapy and rehabilitation in oral cancer.In Vivo 27:401-4

16. Miller A (2020) Returning to work after head and neck cancer. Cur OpinOtolaryngolHead Neck Surg28:155-1https://doi.org/10.1097/M00.0000000000000628

17. Wolvers MDJ, Leensen MCJ, Groeneveld IF et al (2018)Predictors for earlier return to work of cancer patients. J Cancer Surviv12:169-1https://doi.org/10.1007/s11764-017-0655-7

18. Greidanus MA, de Boer AGEM, de Rijk AE et al (2018)Perceived employer-related barriers and facilitators for work participation of cancer survivors: A systematic review of employers' and survivors' perspectives. Psychooncology27:725-7https://doi.org/10.1002/pon.4514

19. Fitch MI, Nicoll I (2019) Returning to work after cancer: Survivors', caregivers', and employers' perspectives. Psychooncology28:792-79https://doi.org/10.1002/pon.5021

20. Chen YJ, Lai YH, Lee YH et al (2021)Impact of illness perception, mental adjustment, and sociodemographic characteristics on return to work in patients with head and neck cancer. Support Care Cancer29:1519-1526.https://doi.org/1007/s00520-020-05640-5 
21. Lee YH, Chang KH, Escorpizo Ret al (2019)Accuracy of the World Health Organization Disability Assessment Schedule 2.0 (WHODAS2.0) score as an objective assessment tool for predicting returnto-work status after head and neckcancer in male survivors. Support Care Cancer27:433441.https://doi.org/1007/s00520-018-4322-y

22. Giuliani M, Papadakos J, Broadhurst M et al (2019)The prevalence and determinants of return to work in head and neck cancer survivors. Support Care Cancer27:5395https://doi.org/10.1007/s00520-018-4343-6

23. Dewa CS, Trojanowski L, Tamminga SJ et al (2018)Work-related experiences of head and neck cancer survivors: an exploratory and descriptive qualitative study. DisabilRehabil 40:125212https://doi.org/10.1080/09638288.2017.1291764

24. Dewa CS, Trojanowski L, Tamminga SJ et al (2016)Advice about work-related issues to peers and employers from head and neck cancer survivors. PLoS One11:e0152944.https://doi.org/1371/journal.pone.0152944

25. Karnofsky DA, Abelmann WH, Craver LF, Burchenal JH (1948) The use of the nitrogen mustards in the palliative treatment of carcinoma with particular reference to bronchogenic. Cancer1:6346https://doi.org/10.1002/1097-0142(194811)1:4<634::AID-CNCR2820010410>3.0.C0;2-L

26. Rodriguez AM, Komar A, Ringash J et al (2019)A scoping review of rehabilitation interventions for survivors of head and neckcancer.DisabilRehabil41:20932107.https://doi.org/1080/09638288.2018.1459880

27. KiasuwaMbengi R, Otter R, Mortelmans $\mathrm{K}$ et al (2016) Barriers and opportunities for return-to-work of cancer survivors: time for action-rapid review and expert consultation. Syst Rev 5:35. https://doi.org/1186/s13643-016-0210-z

28. Tiedtke CM, Dierckx de Casterlé B, Frings-Dresen MHW et al (2017) Employers' experience of employees with cancer: trajectories of complex communication. J Cancer Surviv 11:562-5 https://doi.org/10.1007/s11764-017-0626-z

29. National Comprehensive Cancer Network (2003) Distress managementclinical practice guidelines. J Natl ComprCancNetw1:344-74.https://doi.org/6004/jnccn.2003.0031

30. Hawkes AL, Hughes KL, Hutchison SD, Chambers SK (2010)Feasibility of brief psychological distress screening by acommunity-based telephone helpline for cancer patients andcarers. BMC Cancer10:14.https://doi.org/1186/1471-2407-10-14

31. Tang LL, Zhang YN, Pang Y, Zhang HW, Song LL (2005) Validationand reliability of Distress Thermometer in Chinese cancerpatients. Chin J Cancer Res 23:54-5https://doi.org/10.1007/s11670011-0054-y

32. Rodriguez CS (2001) Pain measurement in the elderly: a review. Pain ManagNurs 2:3846.https://doi.org/1053/jpmn.2001.23746

33. Ferraz MB, Quaresma MR, Aquino LR et al (1990)Reliability of pain scales in the assessment of literate and illiterate patients with rheumatoid arthritis. J Rheumatol 17:1022-24. 
34. Johnsson A, Fornander T, Rutqvis, LE, Olsson M (2010) Factors influencing return to work: A narrative study of women treated for breast cancer. Eur J Cancer Care19:317-

323.https://doi.org/1080/02841860802477899

35. Nilsson M, OlssonM, Wennman-Larsen A, Petersson LM, Alexanderson K (2011)Return to work after breast cancer: women's experiences of encounters with different stakeholders. EurJ Oncol Nurs15:267-274.https://doi.org/1016/j.ejon.2011.03.005

36. Bouknight RR, Bradley CJ, Luo Z (2006) Correlates of return to work for breast cancer survivors. J Clin Oncol24:345-3https://doi.org/10.1200/JC0.2004.00.4929

37. Zafar SY, Peppercorn JM, Schrag D et al (2013)The financial toxicity of cancer treatment: a pilot study assessing out-of-pocket expenses and the insured cancer patient's experience. Oncologist18:381-390.https://doi.org/1634/theoncologist.2012-0279

38. Mady LJ, Lyu L, Owoc MS et al (2019)Understanding financial toxicity in head and neck cancer survivors. Oral Oncol95:187-1https://doi.org/10.1016/j.oraloncology.2019.06.023

39. Chen YY, Wang CC, Wu WT et al (2020)Trajectories of returning to work and its impact on survival in survivors with oral cancer: a 5-year follow-up study. Cancer126:122512https://doi.org/10.1002/cncr.32643

40. Oyeflaten I, Lie SA, Ihlebak CM, Eriksen HR (2014) Prognostic factors for return to work, sickness benefits, and transitions between these states: a 4-year follow-up after work-related rehabilitation. J OccupRehabil24:199-https://doi.org/10.1007/s10926-013-9466-5 